\title{
Current PBPK Models: Are They Predicting Tissue Drug Concentration Correctly?
}

\author{
Manuel Ibarra ${ }^{1} \cdot$ Marta Vázquez $^{1} \cdot$ Pietro Fagiolino $^{1}$ (i)
}

Accepted: 4 October 2020 / Published online: 17 October 2020

(c) The Author(s) 2020

Physiologically based pharmacokinetic (PBPK) models have been receiving extensive attention from biomedical scientific journals for the last 15 years. Even though the concept was first introduced by Teorell [1], recent improvements in computing power have led to an explosive development and implementation of several software platforms containing such models at their core [2-5]. These tools are being increasingly implemented in drug discovery and development, as both the industry and the regulating agencies embrace their application for specific assessments such as drug-drug interactions and dosage recommendations in specific sub-populations $[6,7]$. The reason for such interest is that PBPK models have been established as valid tools in the instrumentation of "bottom-up" and "middle-out" approaches, where the pharmacokinetic profile of a compound for a non-explored scenario can be simulated using previous knowledge of the drug and the organism, eventually integrating in-vitro experiments. This allows prior evaluation of several factors that can affect drug pharmacokinetics such as the dosage form, administration route, food intake, and comedication, and individual characteristics such as ethnicity, age, sex, and disease state [8].

Parameter optimization in PBPK modeling is routinely carried out by the adjustment of simulated concentrations to the experimental blood or plasma concentration-time profiles. Commonly, drug blood concentrations displayed in these platforms belong to both the central vein and the artery but not to peripheral veins, which are the usual sampling site in clinical trials. Several researchers became aware of this aspect and proposed some modifications to the model for the purpose of estimating the correct arteriovenous difference of drug concentrations [9-11].

Pietro Fagiolino

pfagioli@fq.edu.uy

1 Pharmaceutical Sciences Department, Faculty of Chemistry, Universidad de la República, P.O.Box 1157, 11800 Montevideo, Uruguay
Nevertheless, the most important concentration to be assessed in silico, and then correlated with the in vivo profile, should be the extravascular concentration, at the site where most drugs will be acting to produce either therapeutic or toxic effects. These sites could be located in the interstitial space (external face of the cell membrane) or in the intracellular space. Hence, a better pharmacokinetic/pharmacodynamic relationship could be attained from concentrations at the action sites and not from peripheral veins. In fact, this should be the main goal for such PBPK modeling: to predict effective and safe treatments and not to forecast plasma drug concentrations anywhere along the circulatory system. Unfortunately, even though great efforts have been made to predict extravascular tissue drug concentrations using perfusion and permeability rate-limited models with appropriate tissue/plasma partition coefficients, these models are still unable to provide accurate predictions for an individual under different physiologic (i.e., circadian rhythm of the cardiac output distribution) or physiopathologic (i.e., ischemia) states.

Several reports about the refractoriness to antimicrobial treatments were published in some populations $[12,13]$ and in the same individual under different clinical states [14], or with altered blood perfusion in a region of their bodies $[15,16]$. These reports provided evidence of dissimilar drug access to the interstitial space of tissues in relation to healthy tissues. Our research group intended to simulate ciprofloxacin in ischemic and healthy tissues with lower blood perfusion [16] in respect to healthy tissues with normal blood flow using the software given in a recent publication [17]. We were unable to detect any change in the amount of drug partitioned into both tissues (ischemic and healthy) except for their time-dependent profile. However, when we modified the algorithm of the program accordingly to the proposal displayed below, simulated extravascular tissue concentrations of ciprofloxacin exhibited a good correlation with the experimental healthy and ischemic tissues obtained using a microdialysis technique [16]. 
In our view, the origin of such predictive failures lies in the method of exchange of substances between intra- and extravascular spaces proposed in these models. Here, we retrieve the differential equations dealing with the systemic amount $(X)$ balance and the exchange of a drug at a noneliminating tissue $(T)$ :

$\frac{\mathrm{d} X_{\text {Artery }}}{\mathrm{d} t}=k_{\mathrm{VA}} \cdot X_{\mathrm{V}}-\left(\sum_{j}^{n} k_{\mathrm{AT}, j}\right) \cdot X_{\mathrm{A}}$

$\frac{\mathrm{d} X_{\text {Tintravascular }}}{\mathrm{d} t}=k_{\mathrm{AT}} \cdot X_{\mathrm{A}}-k_{\mathrm{Tivev}} \cdot X_{\mathrm{Tiv}}+k_{\mathrm{Teviv}} \cdot X_{\mathrm{Tev}}-k_{\mathrm{Tv}} \cdot X_{\mathrm{Tiv}}$
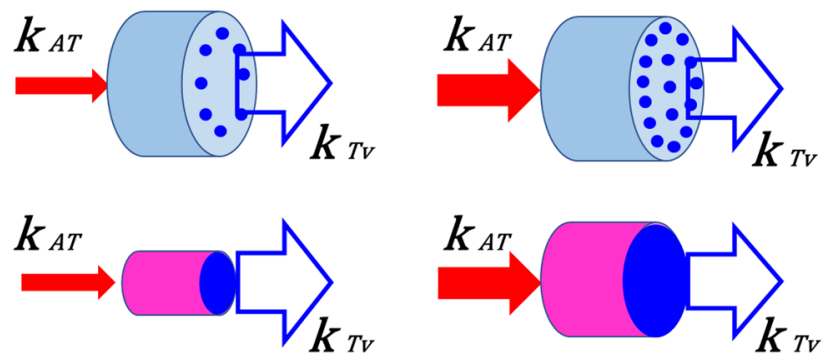

Fig. 1 Graphical representation of a tissue under low (left side) or high (right side) consumption of oxygen in a hypothetical constant cardiac output. Blood flowing through a higher fraction of the capillary bed could be viewed as a wider cylinder of constant length voiding its content at the same rate as the thinner cylinder, which would void to tissue vein the blood coming from a lower fraction of perfused capillaries. The first-order rate constant for the tissue output (hollow blue arrows) is only dependent on the blood speed flowing through the tissue but not on the extent of the perfused area $\frac{\mathrm{d} X_{\text {Textravascular }}}{\mathrm{d} t}=k_{\text {Tivev }} \cdot X_{\text {Tiv }}-k_{\text {Teviv }} \cdot X_{\text {Tev }}$

$\frac{\mathrm{d} X_{\mathrm{veinfromT}}}{\mathrm{d} t}=k_{\mathrm{Tv}} \cdot X_{\mathrm{Tiv}}-k_{\mathrm{vTV}} \cdot X_{\mathrm{vT}}$

$\frac{\mathrm{d} X_{\mathrm{Vein}}}{\mathrm{d} t}=k_{\mathrm{vTV}} \cdot\left(\sum_{j}^{n} X_{\mathrm{vT}, j}\right)-k_{\mathrm{VA}} \cdot X_{\mathrm{V}}$

Figures 1 and 2 allow the readers to understand the meaning of first-order rate constants at the tissue level (Eqs. 2-3). The same principle would be applied for the eliminating tissues, by adding into Eq. 3 the kinetic of elimination from their extravascular spaces.

First-order rate constants, $k_{\mathrm{Tv}}$ and $k_{\mathrm{vTV}}$, remain invariant for a given cardiac output (CO), independently of the actual $\mathrm{CO}$ fraction supplied $\left(\sigma_{\mathrm{T}}\right)$. First-order input rate constants served to any tissue, $k_{\mathrm{AT}}$, are dependent on both $\mathrm{CO}$ and their particular $\sigma_{\mathrm{T}}, k_{\mathrm{AT}}$ accounts for the fraction of mass of the drug delivered from the arterial central compartment to a given tissue per time. By moving the notation from the first-order rate constant to clearance, it adopts the following expression: $\sigma_{\mathrm{T}} . \mathrm{CO} / V_{\mathrm{a}}$, with $V_{\mathrm{a}}$ being the arterial volume invariant.

Otherwise, both $k_{\mathrm{Tv}}$ and $k_{\mathrm{vTV}}$ are always invariant for a given $C O$ and for all body tissues. In other words, whatever the actual $\sigma_{\mathrm{T}}$ supplied, those first-order output rate constants from tissues would adopt the same value. This is because circulating blood volume in veins, and in the intravascular space of tissues, comes from those capillaries that are perfused to supply the oxygen demand of the
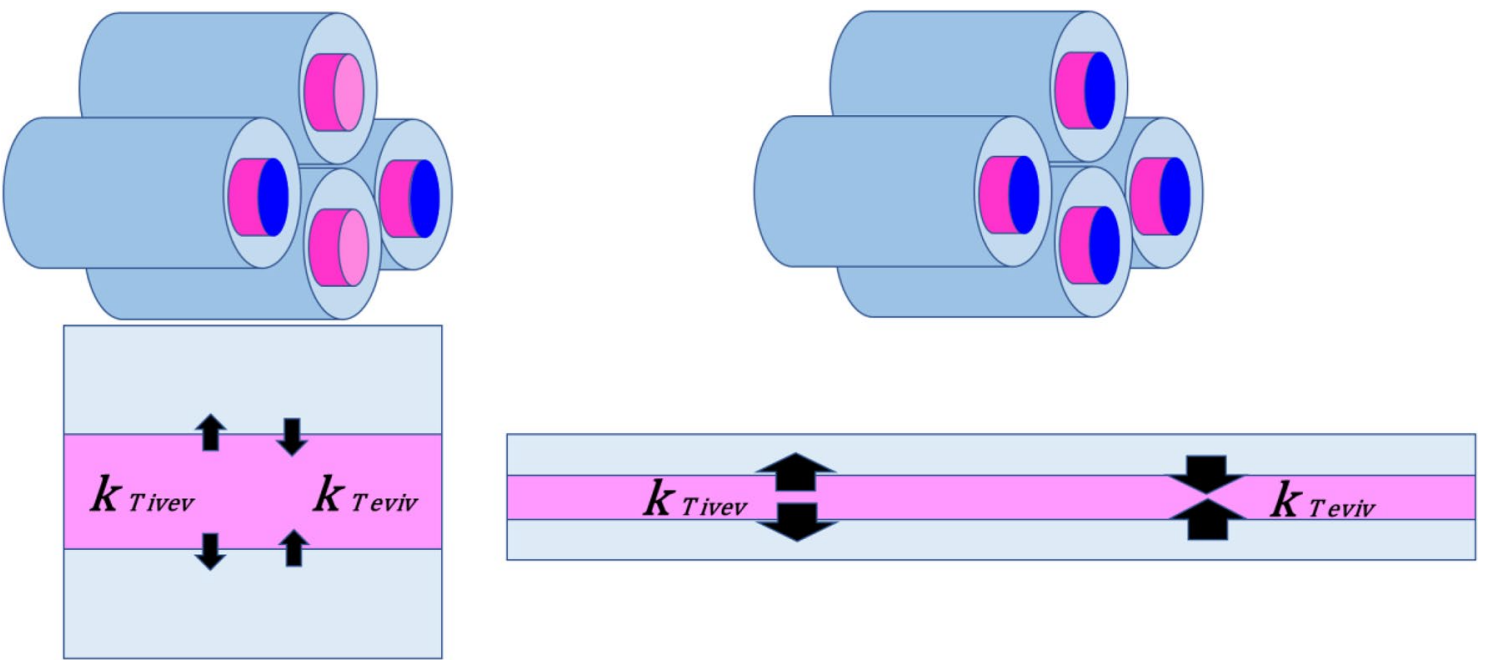

Fig. 2 Perfused capillaries are represented by cylindric tubes ended with blue surfaces. Extravascular surrounding areas exchange their solutes with the intravascular space of the tissue when the blood alternately flows through the perfused capillaries from the whole cap- illary bed. This is viewed as a bidimensional diagram in the bottom of the panel. Once the tissue consumption of oxygen increases (right side), both the number of perfused capillaries and the intra-extravascular interphase area increase, leading to a faster exchange of solutes 
extravascular space of tissues [18]. Consequently, there is a unique value for the output no matter which tissue is considered, and it depends only on CO:

$k_{\mathrm{vTV}}=\sigma_{\mathrm{T}} \cdot \frac{\mathrm{CO}}{V_{\text {vein from T }}}=\sigma_{\mathrm{T}} \cdot \frac{\mathrm{CO}}{V_{\text {perfused capillaries of } \mathrm{T}}}=k_{\mathrm{Tv}}$

Equation 6 enables us to conclude that $k_{\mathrm{TV}}$ equals $k_{\mathrm{vTV}}$, as blood volumes that circulate through capillaries and the vein of tissues are equal. As the actual $\sigma_{\mathrm{T}}$ determines the number of capillaries perfused, it can be stated that there would be a constant $\sigma_{\mathrm{T}} / V_{\text {perfused T }}$ ratio. Considering that cardiac output distribution is better known at a resting state, this basal state of individuals could be adopted to define the first-order output rate constant:

$k_{\mathrm{TV}}=\sigma_{\mathrm{T} \text { basal }} \cdot \frac{\mathrm{CO}}{V_{\text {perfused capillaries of } \mathrm{T} \text { basal }}}=\sigma_{\mathrm{T} \text { basal }} \cdot \frac{\mathrm{CO}}{V_{\text {vein from T basal }}}$

Figure 1 illustrates these concepts for a given tissue under low (left) or high (right) consumption of oxygen. It is important to bear in mind that a constant tissue blood flow implies that blood flows harmoniously through a given fraction of the capillaries, alternating the vessels of the capillary bed in accordance with the oxygen/carbonic anhydride balance at each site, among other mechanisms [19]. Then, diffusion of a drug between intra- and extravascular spaces within the tissue may diminish or increase in both senses ( $k_{\text {Tivev }}$ and $k_{\text {Teviv }}$ ), depending on whether $\sigma_{\mathrm{T}}$ diminishes or increases. Hence, exchanges proceed with slower or faster velocity in response to whether the interphase area decreases or increases, respectively. Figure 2 illustrates the effect on the speed of the drug exchange once the tissue goes from states of low (left) to high (right) consumption of oxygen. This does not imply, however, that the amount of drug partitioned into the tissue from the central artery compartment remains unchanged, as such a partition does not depend on the velocity of the exchange, but on the $\sigma_{\mathrm{T}}$ delivered to the tissue instead.

The previous comments are independent of the type of transfer that takes place at the capillary membrane, whether by simple diffusion, by facilitated or active transport. Any modification in the cardiac output fraction that feeds a tissue only modifies the capillary transfer area; therefore, no transport of limited capacity could be affected as the concentration of drug in the blood remains unchanged. This is the main issue of our proposal because before the drug molecules can be transferred to the extravascular space of a certain tissue, they must first arrive at the tissue capillaries with the potentiality that the physiological or pathophysiological conditions determine. Our point is located before permeating the capillary membrane; it is in how much transfer area is present to fulfill such permeation.
Perfusion rate-limited models, the most broadly used in PBPK modeling, assume instantaneous distribution of a drug into the whole tissue (intra- and extravascular spaces) and between capillaries and venous sections, thus Eqs. 3 and 4 equal zero. Equation 2 can be then simplified as:

$\frac{\mathrm{d} X_{\mathrm{T}}}{\mathrm{d} t}=k_{\mathrm{AT}} \cdot X_{\mathrm{A}}-k_{\mathrm{vTV}} \cdot X_{\mathrm{vT}}$

Being, $X_{\mathrm{vT}}=\frac{k_{\mathrm{Teviv}} \cdot X_{\mathrm{Tev}}}{k_{\text {Tivev }}}$.

Equation 10 is obtained by rewriting Eq. 8 in terms of clearance, or blood flow, and concentrations $(C)$ :

$V_{\mathrm{T}} \cdot \frac{\mathrm{d} C_{\mathrm{T}}}{\mathrm{d} t}=\sigma_{\mathrm{T}} \cdot \mathrm{CO} \cdot C_{\mathrm{A}}-\sigma_{\mathrm{T} \text { basal }} \cdot \mathrm{CO} \cdot C_{\mathrm{vT}} \cdot$

This precedent equation for non-eliminating tissues has a substantial difference from the current equation, in which the same actual $\sigma_{\mathrm{T}}$ is employed in both terms of the right side of the equation. It has an important therapeutic impact as the free drug concentration in blood would not reflect the concentration present in the extravascular space of the target tissue.

The same reasoning could be made for deducing the equation for eliminating tissues; however, it should not be assumed, as it is currently done [20], that the free drug concentration at the extravascular site is equal to the free concentration in the venous plasma leaving the tissue. This is because the $\sigma_{\mathrm{T}} / \sigma_{\mathrm{T} \text { basal }}$ ratio determines a change in the real tissue drug bioavailability in comparison with the basal state. It is easy to understand this fundamental concept if we are aware that physiological changes in blood perfusion of the tissue take place precisely to restore the intracellular oxygen content following its disappearance due to increased cell activity. Drugs, even they are not required by tissue cells, follow the time course of physiological needs for oxygen. Hence, more molecules would enter the cells and would be eliminated from the body if this site had the enzymes or transporters to clear them.

More evidence of dissimilar free drug concentrations between the inside and outside parts of the vessels [21] is provided to change the way we conceive PBPK modeling. We are aware of the importance of such models and the power of their findings, but they need to keep improving so that this useful pharmacokinetic/pharmacodynamic tool is managed with the maximum of certainty.

It should be borne in mind that the previous equations refer to free drug molecules, the only molecules capable of being transferred through capillary membranes. Blood flow distribution among tissues does not alter the free drug concentration in plasma, it just modifies the volume of arterial fluid in tissues, and hence, the amount of drug in 
contact with them. In other words, arterial blood increases the exchange surface in some tissues while decreasing it in others; therefore, free drug molecules at the extravascular spaces are transferred from low- to high-perfused tissues.

Most of the concepts stated here were communicated previously [22-25], nevertheless, PBPK modeling provided us the opportunity to retrieve them and put them into practice without the need to perform clinical trials. We are confident that readers will take our point into account in clarifying the way drug molecules travel in living bodies and will be able to write appropriate algorithms to reproduce this in silico.

\section{Declarations}

Funding No funds were received for this work.

Conflict of interest Manuel Ibarra, Marta Vázquez, and Pietro Fagiolino have no conflicts of interest that are directly relevant to the content of this commentary.

Ethics approval Not applicable.

Data Availability and Material Not applicable.

Consent to participate Not applicable.

Consent for publication Not applicable.

Code Availability Not applicable.

Authors' Contribution All the coauthors participated in the same proportion with the manuscript and they agree with the principles here outlined.

Open Access This article is licensed under a Creative Commons Attribution-NonCommercial 4.0 International License, which permits any non-commercial use, sharing, adaptation, distribution and reproduction in any medium or format, as long as you give appropriate credit to the original author(s) and the source, provide a link to the Creative Commons licence, and indicate if changes were made. The images or other third party material in this article are included in the article's Creative Commons licence, unless indicated otherwise in a credit line to the material. If material is not included in the article's Creative Commons licence and your intended use is not permitted by statutory regulation or exceeds the permitted use, you will need to obtain permission directly from the copyright holder. To view a copy of this licence, visit http://creativecommons.org/licenses/by-nc/4.0/.

\section{References}

1. Teorell T. Kinetics of distribution of substances administered to the body. I. The extravascular modes of administration. Arch Int Pharmacodyn Ther. 1937;57:205-25.

2. Agoram B, Woltosz WS, Bolger MB. Predicting the impact of physiological and biochemical processes on oral drug bioavailability. Adv Drug Deliv Rev. 2001;50:S41-67.
3. Jones HM, Parrott N, Jorga K, Lavé T. A novel strategy for physiologically based predictions of human pharmacokinetics. Clin Pharmacokinet. 2006;45:511-42.

4. Jamei M, Marcinlak S, Feng K, Barnett A, Tucker G, RostamiHodjegan A. The Simcyp ${ }^{\circledR}$ population-based ADME simulator. Expert Opin Drug Metab Toxicol. 2009;5:211-23.

5. Kuepfer L, Niederalt C, Wendl T, Schlender JF, Willmann S, Lippert J, et al. Applied concepts in PBPK modeling: how to build a PBPK/PD model. CPT Pharmacometrics Syst Pharmacol. 2016;5:516-31.

6. Jones HM, Gardner IB, Watson KJ. Modelling and PBPK simulation in drug discovery. AAPS J. 2009;11:155-66.

7. Zhao P, Zhang L, Grillo JA, Liu Q, Bullock JM, Moon YJ, et al. Applications of physiologically based pharmacokinetic (PBPK) modeling and simulation during regulatory review. Clin Pharmacol Ther. 2011;89:259-67.

8. Hartmanshenn C, Scherholz M, Androulakis IP. Physiologicallybased pharmacokinetic models: approaches for enabling personalized medicine. J Pharmacokinet Pharmacodyn. 2016;43:481-504.

9. Levitt DG. Physiologically based pharmacokinetic modeling of arterial-antecubital vein concentration difference. BMC Clin Pharmacol. 2004;4:2.

10. Musther H, Gill KL, Chetty M, Rostami-Hodjegan A, Rowland M, Jamei M. Are physiologically based pharmacokinetic models reporting the right Cmax? Central venous versus peripheral sampling site. AAPS J. 2015;17:1268-79.

11. Huang W, Isoherranen N. Sampling site has a critical impact on physiologically based pharmacokinetic modeling. J Pharmacol Exp Ther. 2020;372:30-45.

12. Toma O, Suntrup P, Stefanescu A, London A, Mutch M, Kharasch E. Pharmacokinetics and tissue penetration of cefoxitin in obesity: implications for risk of surgical site infection. Anesth Analg. 2011;113:730-7.

13. Joukhadar C, Stass H, Müller-Zellenberg U, Lackner E, Kovar F, Minar E, et al. Penetration of moxifloxacin into healthy and inflamed subcutaneous adipose tissues in humans. Antimicrob Agents Chemother. 2003;47:3099-103.

14. Joukhadar C, Frossard M, Mayer BX, Brunner M, Klein N, Siostrzonek $\mathrm{P}$, et al. Impaired target site penetration of beta-lactams may account for therapeutic failure in patients with septic shock. Crit Care Med. 2001;29:385-91.

15. Joukhadar C, Dehghanyar P, Traunmüller F, Sauermann R, MayerHelm B, Georgopoulos A, et al. Increase of microcirculatory blood flow enhances penetration of ciprofloxacin into soft tissue. Antimicrob Agents Chemother. 2005;49:4149-53.

16. Joukhadar C, Klein N, Frossard M, Minar E, Stass H, Lackner $\mathrm{E}$, et al. Angioplasty increases target site concentrations of ciprofloxacin in patients with peripheral arterial occlusive disease. Clin Pharmacol Ther. 2001;70:532-9.

17. Sadiq MW, Nielsen EI, Khachman D, Conil JM, Georges B, Houin $\mathrm{G}$, et al. A whole-body physiologically based pharmacokinetic (WB-PBPK) model of ciprofloxacin: a step towards predicting bacterial killing at sites of infection. J Pharmacokinet Pharmacodyn. 2017;44:69-79.

18. Jacob M, Chappell D, Becker BF. Regulation of blood flow and volume exchange across the microcirculation. Crit Care. 2016;20:319. https://doi.org/10.1186/s13054-016-1485-0.

19. Secomb TW. Theoretical models for regulation of blood flow. Microcirculation. 2008;15:765-75.

20. Jones HM, Rowland-Yeo K. Basic concepts in physiologically based pharmacokinetic modeling in drug discovery and development. CPT Pharmacometrics Syst Pharmacol. 2013;2:e63. https ://doi.org/10.1038/psp.2013.41.

21. Langer O, Karch R, Müller U, Dobrozemsky G, Abrahim A, Zeitlinger M, et al. Combined PET and microdialysis for in vivo 
assessment of intracellular drug pharmacokinetics in humans. J Nucl Med. 2005;46:1835-41.

22. Fagiolino P, Eiraldi R, Vázquez M. The influence of cardiovascular physiology on dose/pharmacokinetic and pharmacokinetic/pharmacodynamic relationships. Clin Pharmacokinet. 2006;45:433-48.

23. Fagiolino P. Multiplicative dependence of the first order rate constant and its impact on clinical pharmacokinetics and bioequivalence. Eur J Drug Metab Pharmacokinet. 2004;29:43-9.
24. Fagiolino P, Wilson F, Samaniego E, Vázquez M. In vitro approach to study the influence of the cardiac output distribution on drug concentration. Eur J Drug Metab Pharmacokinet. 2003;28:147-53.

25. Fagiolino P. The influence of cardiac output distribution on the tissue/plasma drug concentration ratio. Eur J Drug Metab Pharmacokinet. 2002;27:79-81. 